Original Article

\title{
Prognostic Factors for Decompressive Hemicraniectomy in Severe Traumatic Brain Injury Patients with Traumatic Mass Lesions: A Prospective Experience from a Developing Country
}

\author{
Naseer-ud-Din Ghulam1, Kashif Ali Sultan ${ }^{1}$, Mohammad Ashraf ${ }^{1,2}$, Nabeel Choudhary ${ }^{1}$ \\ Usman Ahmad Kamboh', Nazir Ahmed ${ }^{1}$, Muhammad Asif Raza', Waqas Latif ${ }^{3}$ \\ Syed Shahzad Hussain ${ }^{1}$, Naveed Ashraf ${ }^{1}$ \\ Department of Neurosurgery, ${ }^{1}$ Allama Iqbal Medical College, Jinnah Hospital, ${ }^{3}$ University of Health Sciences, \\ Lahore, Pakistan. ${ }^{2}$ Wolfson School of Medicine, University of Glasgow, Scotland, United Kingdom
}

\begin{abstract}
Objective: To evaluate the prognostic factors affecting functional clinical outcomes in severe traumatic brain injury patients with traumatic mass lesions undergoing decompressive hemicraniectomy (DHC).

Materials and Methods: A prospective cohort of 85 patients of severe traumatic brain injury patients with traumatic mass lesions underwent a unilateral decompressive hemicraniectomy. Functional outcomes were assessed using the Glasgow Outcome Score at 28 days, 3 months, and 6 months. Bivariate analysis (chisquared) was used to identify parameters that resulted in poor outcomes and multiple regression was used to identify independent factors predicting poor outcomes.

Results: 85 patients were recruited. Functional outcomes were dichotomised as favourable (Glasgow Outcome Score of $4-5$ ) and poor (Glasgow Outcome Score 1-3) and evaluated at 28 days, 3 and 6 months. A total of 59 patients expired (69.4\%). Bivariate analysis revealed GCS $3-5$ at presentation $(P=0.002)$, midline shift greater than $7.5 \mathrm{~mm}(P<0.001)$, the volume of the mass lesion more than $40 \mathrm{ml}(P=0.006)$ resulted in a poor outcome. Age dichotomised to less than or more than 50 years bordered statistical significance $(P=0.063)$. Only GCS at presentation and midline shift were independent factors that predicted poor outcomes when controlling for covariates. Receiver Operating Characteristic analysis identified a midline shift of $7.5 \mathrm{~mm}$ was an optimal cut off having a sensitivity of $88.7 \%$ and a specificity of $55.2 \%$ for a poor functional outcome.

Conclusion: Decompressive hemicraniectomy can be a lifesaving intervention in managing severe traumatic brain injury patients with traumatic mass lesions. However, its use needs to be employed judiciously. We present clinical and radiological prognostic factors that can aid decision-making and should be employed with familial input when considering DC for STBI patients with traumatic mass lesions.
\end{abstract}

Keywords: Decompressive Craniectomy, Severe Traumatic Brain Injury, Traumatic Mass Lesion, Intracranial Pressure, Glasgow Outcome Scale.

Corresponding Author: Mohammad Ashraf

Wolfson School of Medicine

University of Glasgow, Scotland, United Kingdom

Email: mohammad_5676@hotmail.com
Date of Revision: 20-12-2021

Date of Acceptance: 29-12-2021

Date of Online Publishing: 31-12-2021

Date of Print: 31-12-2021

Date of Submission: $10-12-2021$

DOI: $10.36552 /$ pjns.v25i4.606 


\section{INTRODUCTION}

Traumatic Brain Injury (TBI) is a leading cause of mortality and morbidity worldwide with intense cognitive and psychological consequences; it is a substantial global tragedy with a burden of 10 million annual sufferers, leading to a catastrophic socio-economic impact. ${ }^{1,2}$ The developing world has the highest incidences of TBI globally and one that is increasing. ${ }^{3,4}$ In such countries, the aetiology of $\mathrm{TBI}$ is predominantly road traffic accidents due to inadequate regulation, underage driving, no formal traffic education, and substandard traffic safety regulation.

Raised intracranial pressure (ICP) refractory to medical management accounts for $10-15 \%$ of severe TBI (sTBI) patients. ${ }^{5}$ It is generally accepted that patients with a Glasgow Coma Score (GCS) of 9 to 15 (moderate to mild TBI) have a low risk of raised ICP and its subsequent clinical sequelae, whilst those with sTBI (GCS 3 to 8) may have evidence of raised ICP even in the absence of a surgical lesion. ${ }^{6}$ Decompressive craniectomy (DC) is a surgical procedure performed to immediately decrease ICP and is indicated in brain oedema, acute subdural haematoma (ASDH), and other conditions associated with increased ICP. The procedure involves removing part of the calvarium and may include duraplasty to allow room for expansion of intracranial contents, thus reducing ICP. When salvageable, the bone flap is either preserved in freezers or cases of smaller pieces of bone in the subcutaneous tissue of the abdomen. Depending on the centre, cranioplasty is performed with methyl methacrylate or titanium plates when the bone flap is not reusable.

DC can prevent secondary brain injury due to raised ICP and decreased cerebral perfusion pressure, which significantly contributes to sTBI associated mortality and morbidity. DC may also improve oxygen delivery to brain parenchyma by improving blood flow. ${ }^{7}$ With clinical and or/ radiological evidence of relevant acute spaceoccupying lesions, early DC can effectively decrease ICP. ${ }^{8}$ DC is a highly controversial topic within neurosurgery, and indications remain challenging in the emergency setting, with arguments from reports of a high proportion of poor functional outcomes.9,10 The most suitable way to lower raised ICP to the normal range is to address the cause. DC for STBI has also been shown to improve mortality compared to conventional ventriculostomy with ICU management significantly. ${ }^{11}$

A paucity of literature exclusively studies STBI (GCS $3-8$ ) patients with traumatic mass lesions. Cohorts have often been heterogeneous regarding the radiological severity of brain injury. Unfortunately, these patients represent the most severe injury and have the worst prognosis. Given the scarcity of studies, especially from developing countries where the incidence of STBI is highest globally, its impact can be argued to be even more detrimental not only to the individual and their family but society. This study aimed to present prognostic factors for the functional outcomes in traumatic mass lesion sTBI patients who underwent a large unilateral frontaltemporal-parietal decompressive hemicraniectomy (DHC) with duraplasty for a closed head injury. Clinical outcomes and predictive factors were analysed at 28 days, 3 months, and 6 months. Functional outcomes at 3 months are recognised as a powerful independent predictor of long-term outcomes in sTBI. ${ }^{12}$

\section{MATERIALS AND METHODS}

\section{Study Setting}

We recruited patients prospectively over 1 year (February 2019- January 2020) who presented to our neurosurgery department and met our inclusion and exclusion criteria. In this study, we recruited STBI patients with unilateral traumatic mass lesions. Our Institutional Review Board approved the study before conduction. Our national language (non-English) leaflet was used 
to explain the objective of the research to all patients or relatives and take informed consent. Relevant data were collected on dedicated proforma.

\section{Inclusion Criteria}

We studied patients of either gender aged 18 to 60 years who presented within 72 hours of a severe and non-penetrating traumatic brain injury. All patientshad a Glasgow Coma Score of 8 or less. Patients had a high - density lesion with a volume of $25 \mathrm{ml}$ or more on CT scan, and a midline shift greater than $5 \mathrm{~mm}$.

\section{Exclusion Criteria}

We excluded patients with any prior illness that limited their survival to 1 year after ictus, patients with extradural haematomas, haemodynamic and or respiratory instability and those patients with bilaterally dilated fixed pupils.

\section{Surgical Procedure}

A standard surgical procedure of frontaltemporal-parietal decompressive hemicraniectomy was employed (Figure 1).

Following anaesthesia, a sizeable frontaltemporal-parietal trauma flap was made using the

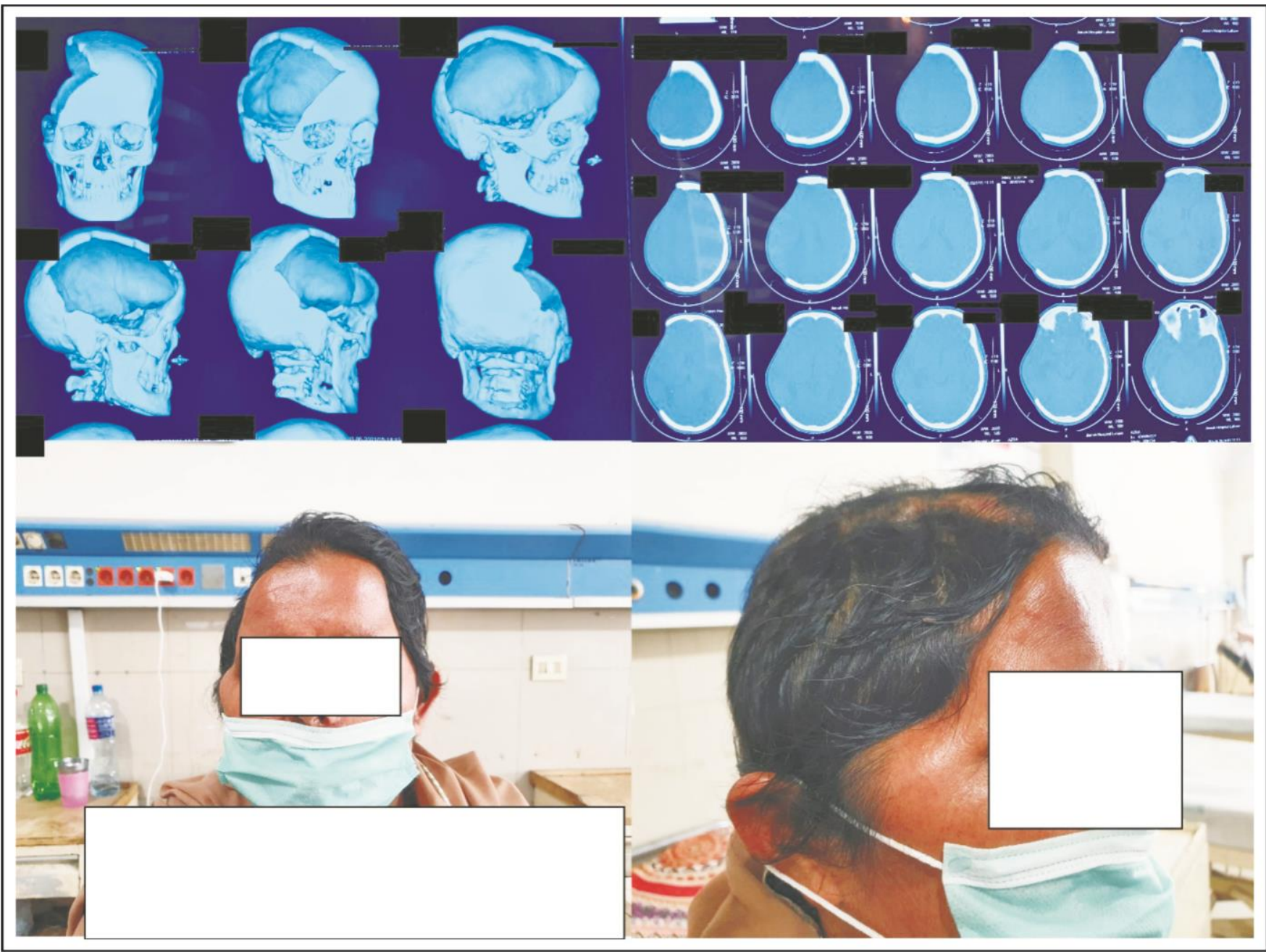

Figure 1: Patient presenting GCS of 6 underwent a right side hemicraniectomy which was followed by a 'good' recovery. Preoperative CT scan and 3D reconstruction are presented. Patient images were attached with informed consent. 
question mark incision. Following burr holes, a bone flap of $15 \mathrm{~cm}$ (anterior-posterior), $12 \mathrm{~cm}$ (height) was raised, removed, and stored in a refrigerator to be used as a template for cranioplasty. Durotomy was performed, the mass lesion was evacuated, and haemostasis was achieved using bipolar cautery. Duroplasty was performed using peri-cranial fascia. Intravenous (IV) antibiotics (Augmentin and Ceftriaxone) and were delivered 30 minutes before DHC. All patients were subsequently ventilated in our neurocritical care unit and were followed by the authors to assess their functional outcomes using the Glasgow Outcome Scale (GOS). Later, cranioplasty was performed with polymethylmethacrylate.

\section{Statistical Analysis}

Data were analysed using Statistical Package for Social Sciences (SPSS) version 23. Mean \pm SD is provided for quantitative variables including age, time since the injury to decompressive craniectomy, GCS at presentation, GOS at 28 days and 3 months, CT scan findings such as volume of traumatic mass lesion midline shift. In addition, frequency and percentages were calculated for gender, mechanism of injury, preoperative CT scan findings, and complications. Differences between groups were considered significant if a $\mathrm{p}$-value of less than 0.05 was observed. Functional outcome was dichotomised to good or favourable outcome defined as either 4 or 5 on the Glasgow Outcome Scale. An unfavourable or poor outcome was defined as a GOS of 1 to 3 (death, persistent vegetative state, and severe disability, respectively).

Bivariate analysis was performed for each parameter (GCS at presentation, midline shift, CT scan findings etc.) using the Chi-squared test, and associated $p$-values are provided in table 1, stratifying parameters by good and poor. A receiver operating characteristics (ROC) analysis was performed to identify the cut-off values of midline shift for poor outcomes.
A univariate simple logistic regression was used to determine the relationship between study variables and poor outcomes (table 2). Factors deemed significant in the univariate model were used to perform multiple stepwise logistic regression (Table 3).

\section{RESULTS}

\section{Patient Demographics}

Eighty - five patients met our inclusion and exclusion criteria over the study duration. The mean age for these patients was 40.18 years and included 69 (81.2\%) males and 16 (18.8\%) females. The average time between injury and DC was $9.98 \pm 10.97$ hours (mean/SD). All patients suffered from a road traffic accident.

\section{Radiological Findings}

CT scan showed 34 patients (40\%) had an acute subdural haematoma (ASDH), 9 patients (10.6\%) had contusions, 5 patients had an intracerebral haemorrhage $(\mathrm{ICH})(5.9 \%)$, and 37 patients (43.5\%) had a both ASDH and contusions.

\section{Mortality and Outcome}

A total of 59 patients (69.4\%) expired one month after surgery. After 3 months of surgery, 62 patients $(72.9 \%)$ had passed away making the overall survival rate 23 (27.1\%). Glasgow outcome scale measured at 28 days showed two patients in a vegetative state and three patients severely disabled. At three months, no patient was in a vegetative state or severely disabled. GOS at 3 months revealed 62 patients (72.9\%) having unfavourable outcomes, whilst 23 patients (27.1\%) had a good outcome. At 3 months, 13 patients had a GOS of 5 , and 10 patients had a GOS of 4 . At 6 months 15 patients had a GOS of 5 , whilst 8 patients remained at GOS 4 .

GCS at presentation had a substantial impact on patients undergoing a DC for STBI, with favourable outcomes observed in $36.7 \%$ of 
Table 1: Showing Baseline Patients' Characteristics and Bivariate Analysis of GCS, Age, Mass Lesion Volume, and Midline Shift with Favourable Outcomes at 3 Months.

\begin{tabular}{|c|c|c|c|c|c|}
\hline Variables & Categories & $\begin{array}{l}\text { Poor Outcome } \\
\quad(n=62)\end{array}$ & $\begin{array}{l}\text { Good Outcome } \\
\qquad(n=23)\end{array}$ & $\begin{array}{l}\text { Overall } \\
(n=85)\end{array}$ & p-value \\
\hline Age, years (Mean $\pm S D)$ & & $42.3 \pm 14.9$ & $36.7 \pm 13.9$ & $40.8 \pm 14.8$ & 0.120 \\
\hline \multirow{2}{*}{ Gender, n (\%) } & Male & 49 (79.0\%) & 20 (87.0\%) & 69 (81.2\%) & \multirow{2}{*}{0.540} \\
\hline & Female & $13(21.0 \%)$ & $3(13.0 \%)$ & 16 (18.8\%) & \\
\hline $\begin{array}{l}\text { Time since the Injury, Hours } \\
\text { (mean } \pm \mathrm{SD} \text { ) }\end{array}$ & & $10.1 \pm 10.9$ & $9.2 \pm 8.9$ & $9.98 \pm 10.97$ & 0.317 \\
\hline GCS (mean \pm SD) & & $6.0 \pm 1.48$ & $7.09 \pm 0.85$ & $6.28 \pm 1.42$ & $0.001 *$ \\
\hline \multirow{2}{*}{ GCS } & $3-5$ & $24(96.0 \%)$ & $1(4.0 \%)$ & 25 (29.4\%) & \multirow{2}{*}{$0.002^{*}$} \\
\hline & $6-8$ & 38 (63.3\%) & $22(36.7 \%)$ & 60 (70.6\%) & \\
\hline \multirow{2}{*}{ Midline Shift } & $\leq 7.5 \mathrm{~mm}$ & 7 (38.9\%) & $11(61.1 \%)$ & $18(21.2 \%)$ & \multirow{2}{*}{$0.001^{*}$} \\
\hline & $>7.5 \mathrm{~mm}$ & 55 (82.1\%) & 12 (17.9\%) & 67 (78.8\%) & \\
\hline \multirow{2}{*}{ Age group } & $\leq 50$ years & $38(66.7 \%)$ & 19 (33.3\%) & 57 (67.1\%) & \multirow{2}{*}{0.063} \\
\hline & $>50$ years & $24(85.7 \%)$ & $4(14.3 \%)$ & 28 (32.9\%) & \\
\hline \multirow{4}{*}{ Mass Lesion Volume } & $\leq 40 \mathrm{ml}$ & $41(65.1 \%)$ & 22 (34.9\%) & 63 (74.1\%) & \multirow{4}{*}{$0.006^{*}$} \\
\hline & $>40 \mathrm{ml}$ & 21 (95.5\%) & $1(4.5 \%)$ & 22 (25.9\%) & \\
\hline & ASDH & 25 (73.5\%) & $9(26.55)$ & 34 (40.0\%) & \\
\hline & Contusion & $6(66.7 \%)$ & 3 (33.3\%) & 9 (10.6\%) & \\
\hline \multirow[t]{2}{*}{ CT Findings } & $\mathrm{ICH}$ & $3(60.0 \%)$ & 2 (40.0\%) & 5 (5.9\%) & \multirow[t]{2}{*}{0.804} \\
\hline & $\begin{array}{l}\text { ASDH + } \\
\text { Contusion }\end{array}$ & 28 (75.7\%) & 9 (24.3\%) & 37 (43.5\%) & \\
\hline
\end{tabular}

*Significant

Table 2: Simple logistic regression analysis showing association of clinical parameters with poor outcome.

\begin{tabular}{lccccccc|} 
Variable & $\boldsymbol{\beta}$ & $\mathbf{S E}$ & Wald $\mathbf{x}^{\mathbf{2}}$ & $\mathbf{p}$-value & OR & \multicolumn{2}{c|}{$\mathbf{9 5 \%} \mathbf{C l}$} \\
Age & 0.026 & 0.017 & 2.404 & 0.121 & 1.027 & 0.993 & 1.062 \\
GCS & -0.711 & 0.239 & 8.845 & $0.003^{*}$ & 0.491 & 0.307 & 0.785 \\
CT Finding & & \multicolumn{7}{c}{ ASDH Reference } \\
Contusion & -0.329 & 0.807 & 0.166 & 0.684 & 0.720 & 0.148 & 3.501 \\
ICH & -0.616 & 0.992 & 0.386 & 0.535 & 0.540 & 0.077 & 3.775 \\
ASDH + Contusion & 0.113 & 0.546 & 0.043 & 0.836 & 1.120 & 0.384 & 3.265 \\
Midline Shift & 1.974 & 0.579 & 11.627 & $0.001^{*}$ & 7.202 & 2.315 & 22.405 \\
\hline
\end{tabular}

$\mathrm{OR}=$ odds ratio, *Significant

Table 3: Stepwise Multivariable Logistic Regression Analysis Showing Association of Clinical Parameters with Poor Outcome.

\begin{tabular}{|lccccccr|} 
Variable & $\boldsymbol{\beta}$ & SE & Wald $\mathbf{x}^{\mathbf{2}}$ & p-value & OR & \multicolumn{2}{c|}{$\mathbf{9 5 \%} \mathbf{~ C l}$} \\
GCS & -0.737 & 0.273 & 7.274 & $0.007^{*}$ & 0.478 & 0.280 & 0.818 \\
Midline Shift & 1.898 & 0.617 & 9.452 & $0.002^{*}$ & 6.670 & 1.989 & 22.263 \\
\hline
\end{tabular}

$\mathrm{AOR}=$ adjusted odds ratio, ${ }^{*}$ Significant

patients with GCS of $6-8$ and only $4 \%$ of those with a GCS 3 to 5 ( $p=0.002)$. A midline shift of less than $7.5 \mathrm{~mm}$ was a positive predicting factor, having favourable outcomes in $61.1 \% \%$ of 
patients, whilst a midline shift of $7.5 \mathrm{~mm}$ or more is a negative predicting factor in STBI with favourable outcomes in only $17.9 \%$ of patients at three months ( $p<0.001)$. The midline shift's optimal cut-off value was $7.5 \mathrm{~mm}$ with $88.7 \%$ sensitivity and $52.2 \%$ specificity. Furthermore, the area under the curve (AUC) was 0.790 with a Confidence Interval of $0.683-0.897$ ( $p$-value $<0.001)$, which shows that midline shift is a suitable parameter for determining the poor outcome. $33.3 \%$ of patients aged 50 years or less had a favourable outcome, whilst only $14.3 \%$ of those over 50 years had a favourable outcome $(p=0.063) .34 .9 \%$ of patients with a mass lesion volume of $40 \mathrm{ml}$ or less had a favourable outcome, whilst $4.9 \%$ of patients with a mass lesion volume greater than $40 \mathrm{ml}$ had a favourable outcome $(p=0.006)$.

\section{Relationship between Parameters and Outcome}

No relationship was found between age, CT scan aetiology of the mass lesion (ASDH, contusion, and $\mathrm{ICH}$ ), and poor outcome. Low GCS score on presentation and a higher midline shift were significant factors increasing the risk of poor patient outcome. The volume of the lesion was excluded due to high collinearity with midline shift on matrix plots. When adjusting for covariates: GCS and midline shift were independent factors associated with poor outcomes.

A one $\mathrm{mm}$ increase in midline shift increased the odds of having a poor outcome by 6.67 times (95\% confidence interval 1.99 to 22.26). A unit increase in GCS score decreased the odds of having a poor by almost half (52.2\%) (95\% confidence interval $18.2 \%$ to $72 \%)$.

\section{Complications}

The complications observed in our cohort included ventilator-associated pneumonia (VAP) ( $n=42,49.4 \%)$. Acute kidney injury (AKI) and pneumothorax occurred in 4 patients (4.7\%) and hydrocephalus in 1 (1.2\%). By three months, $27.1 \%$ of patients had a favourable outcome, whilst $72.9 \%$ did not.

\section{Followup and Cranioplasty}

The mean time between $\mathrm{DHC}$ and cranioplasty is 10.35 months (median 9.5, range $6-17$ months). At 6 months; of the 15 patients who had a GOS of 5, 1 patient reported persistent headaches. 2 patients reported cognitive deficits (including 1 patient with headache), and 2 patients reported psychosomatic disturbances (including 1 patient who also reported headaches). Following cranioplasty, headaches resolved in all patients. Psychosomatic disturbances and cognitive deficits remained in half of those who reported them. Similarly, at 6 months, 8 patients with GOS 4 suffered from hemiparesis, including 1 patient who reported dysphasia. These were due to their primary brain injury and thus, did not improve after cranioplasty.

\section{DISCUSSION}

DC for STBI has been a subject of controversy. It has been studied internationally but remains a last tier of management for raised ICP refractory to medical management. We studied and recruited patients based on a GCS of 8 or less and CT scan findings of the traumatic mass lesion and midline shift. ${ }^{13}$ Numerous studies have shown that early DC reduces mortality, critical care stay and improves the Barthel index (a measure of physical disability. ${ }^{14}$ The clinical outcome of DC in STBI is, however, varied from $7 \%$ to $70 \% .^{15-26}$ This controversy in the literature is partly due to variations in care, selection criteria, type of craniectomy performed (where a large DHC is most effective than other types. ${ }^{27}$ Still, importantly, the disparity between studies is also due to variation in parameters of their patient population. Most studies focusing on STBI are either retrospective or independent of study type, 
have included patients with a GCS greater than 8 on admission. ${ }^{10,14,19,21-23,28}$ The limited number of studies strictly implementing a GCS of 3 to 8 inclusion, such as Park et al. ${ }^{10}$ and Fotakopoulos et $\mathrm{al}_{1}{ }^{14}$ are retrospective. Many authors have included Marshall Grade 2 and 3 patients. ${ }^{19,24,6,29}$ The inclusion of the less severe Marshall Grades and variation of the age range in cohorts of various studies, such as excluding those over the age of 50, accounts for the discrepancy in outcomes.

In our study, we evaluated the outcome of DC in a cohort of STBI patients with traumatic mass lesions. One study conducted by Laghari et al. with 72 patients showed favourable outcomes in $51.4 \%$ of patients. Still, their cohort includes those with moderate TBI and approximately $26 \%$ of patients with extradural haematoma. ${ }^{25}$ While extradural haematoma is usually a complication of mild head injury, ASDH and contusion are associated with severe primary injury. ${ }^{30,31}$ The landmark DECRA trial (a multi-centre randomised controlled trial) compared DC to standard care in diffuse STBI, showing DC while lowering ICP and ICU stay (days); it may not improve mortality and is associated with poor 6-month functional outcomes. ${ }^{24}$ However, DECRA evaluated patients for diffuse injury, included patients with a GCS $>8$ and excluded traumatic mass lesion patients undergoing DC; our cohort included only STBI patients with mass lesions such as ASDH, contusions, and $\mathrm{ICH}$.

Our work demonstrates an association between a GCS and functional outcomes, where those who have a GCS of $3-5$ have poorer functional outcomes than those with a GCS of 6 8. Park et al. ${ }^{10}$ found favourable outcomes from the modified Rankin Scale in only six patients out of a total of $127 \mathrm{sTBI}$ patients. The operative decision was made according to Marshall's CT scan classification (2 to 4 ). The postoperative mortality was $68.5 \%$ (87 patients) and attributed to brain swelling. However, factors associated with a good recovery was a GCS of 6 or more and a younger age, whilst a GCS of $3-5$ was a poor predictor of outcome, and this supports our results; in our cohort, a GCS of $3-5$ only had $4 \%$ of favourable outcomes whilst $36.6 \%$ of those with a GCS of 6-8 had a favourable outcome ( $P=$ 0.002). In our stepwise regression, a one-unit increase in GCS reduced the odds of having a poor outcome by 52.2\%. Additionally, our mortality was also comparable (72.9\%).

When compared to Hosseinali et $\mathrm{al}_{,}{ }^{21}$ although the overall results do not agree with the authors' cohort, which shows a $41 \%$ mortality at one year and unfavourable outcomes in $54.2 \%$ of DC patients, this disparity can be accounted for by the variation in their patients' presenting GCS including those with a GCS of above 8, and exclusion of those with a GCS of $3-4$. When comparing those with a GCS of $6-8$ in the authors' study to ours, a favourable outcome was observed in $45.8 \%$ of Hosseinali et al, which is approximately $10 \%$ more than our study (36.6\%). This further discrepancy may be accounted for by the inclusion of patients with a Rotterdam score of $1-3$, which is a positive predictor of favourable outcome. ${ }^{21}$

Midline shift in proportion and out of proportion to haematoma is known to significantly affect the overall outcome in patients of traumatic brain injury. ${ }^{32}$ Around $40 \%$ of those with a midline shift in proportion to mass lesion have a poor outcome whilst this figure rises to $88 \%$ with a midline shift out of proportion. ${ }^{32}$ The chi-squared exact test confirmed this in our study, with a statistically significant difference in the distribution of patients' midline shift less than $7.5 \mathrm{~mm}$ and those with a midline shift greater than $7.5 \mathrm{~mm}(P<0.001) .38 .9 \%$ of those with a midline shift less than $7.5 \mathrm{~mm}$ had an unfavourable outcome whilst $82.1 \%$ of those with a midline shift greater than $7.5 \mathrm{~mm}$ had an unfavourable outcome. Park et $\mathrm{al}^{10}{ }^{10}$ had similarly classified midline shifts less than $10 \mathrm{~mm}, 10 \mathrm{~mm}$ to $20 \mathrm{~mm}$, and greater than $20 \mathrm{~mm}$. Out of 6 patients with a good outcome, 4 had a midline shift less than 
$10 \mathrm{~mm}$ results, but this was not taken as significant, possibly due to a small sample. Our stepwise regression analysis identified a 1.8 times increase in the odds of a poor outcome for a $1 \mathrm{~mm}$ increase in midline shift. ROC curve analysis showed that a midline shift of $7.5 \mathrm{~mm}$ was an optimal cut - off with a sensitivity of $88.7 \%$ and a specificity of $55.2 \%$ for a poor functional outcome. This has an area under the curve of 0.79, making midline shift a good parameter for prognostication of DC to determine good outcomes.

The volume of traumatic mass lesion contributes to predicting functional outcomes as $34.9 \%$ of those with lesion mass less than $40 \mathrm{ml}$ had a desirable functional outcome. Of those with a mass lesion greater than $40 \mathrm{ml}$, only $4.9 \%$ had a favourable outcome $(P=0.006)$. Large extradural, subdural, and intra-parenchymal haematomas are associated with higher mortality than small intracranial bleeds ${ }^{33}$ and DC following the evacuation of lesions greater than $50 \mathrm{ml}$ with nearly three times worse oddsof mortality ${ }^{19}$. Similarly, a DC for ASDH shows a marked difference in mortality between those with a clot thickness greater than $10 \mathrm{~mm}(40 \%)$ and a clot thickness greater than $20 \mathrm{~mm}$ (85\%). ${ }^{34}$ DC has been shown to prevent brain damage, neurological worsening, and acute oedema following infarctions in patients with traumatic mass lesions. ${ }^{35}$

All our patients underwent DC within 48 hours, and it is known that early DC within 48 hours has better neurological recovery and functional outcomes. ${ }^{36-38}$ Additional factors concerning postoperative care shown to increase the risk of poor outcomes significantly include hypoxia, maintenance of cerebral perfusion pressure, and blood pressure when controlling for other important postoperative care covariates. ${ }^{29}$

Younger age has been observed to be associated with better outcomes in studies of DC, which included patients with a GCS of 8 and above, whilst mortality and disability being higher for GCS of 5 or less upon admission. Still, these works have not studied age specifically in the context of sTBI. ${ }^{25,}{ }^{39-41}$ Age is no doubt a sensitive factor and produces a moral dilemma. There may be a place for age as a prognostic factor on the outcome of DC for sTBI. $33.3 \%$ of those aged 50 or less had a favourable outcome, whilst for those over 50, a favourable outcome was observed in only $14.3 \%$. The $p$-value is 0.063 and borders the significance threshold. A larger sample size may be needed to affirm statistical significance. We are still of the opinion that a patient's age when undergoing DC is an essential factor of outcome and should be considered in the criterion for patient selection. Others have rightly raised that chronological age needs to be replaced with 'physiological age' as chronological age may not trend linearly towards poor health. Anecdotally, we have noticed that in our demographics, life expectancy is as low as the $6^{\text {th }}$ decade of life in the socio-economically most impoverished areas, such as manual labourers and those in the slums. These constitute a large proportion of sTBI patients nationally. Our observation is that with ageing, many of these patients have comorbidities, which go undiagnosed due to lack of access to primary healthcare.

While our study did not have a control group, Rubiano et $\mathrm{al}^{11}$ showed DC to have a better functional outcome on the GOS $(P=0.0002)$ and a lower mortality rate than conservative medical management with ventriculostomy and ICU care. Rubiano et $\mathrm{al}^{11}$ justifies our study and also encourages DC in STBI patients over conservative management. While we are the only centre nationally to employ ICP monitoring in our clinical practice, still, we did not monitor ICP for this very reason, wanting to promote generalisability in our national setting. Compared to developed countries, where ICP monitoring is far more prevalent, our outcomes are broadly similar. ${ }^{24,28,42-}$ 45 Thus, we believe clinical and radiological evaluation of parameters is still equally valuable for decision making in STBI. 
The complications in our study did not appear to influence functional outcomes but ICUs with better infection control, early detection of pneumonia, and other chest complications definitively improve outcomes in different settings. VAP has been shown to have a $40 \%$ prevalence amongst TBI patients in neurosurgical intensive care units, being as high as $51 \%$ in those with STBI. ${ }^{46,47}$ It is estimated if eliminated, it would shift $2.9 \%$ of those having an unfavourable outcome to favourable. ${ }^{46}$ As Fotakopoulos et al, $^{14}$ states, concerns raised with DC include complications which have been reported to include infections (3-7\%), communicating hydrocephalus (20.7\%), subdural hygromas (26\%), brain herniation (27.6\%), and seizures (14\%). ${ }^{48-54}$ Cooper et $\mathrm{al}^{55}$ hypothesised that the poor functional outcomes following DC might be attributed to the increased cerebral blood flow resulting from removing the bone flap, which may obstruct the decompressed brain exacerbating acute oedema; however, this acute increase can also be protective against acute secondary ischaemia. ${ }^{51}$ It is also interesting to note that no patient underwent cranioplasty before 3 months following DC. While complications from lack of cranioplasty can be expected to be higher in an LMIC setting where a patient may be more at risk of injury, this was not the case, and no such complications were observed. We postulate this is due to cultural reasons as caregivers observe extra precaution with these patients and that often, they do not completely re-enter normal routine life. The ideal time for cranioplasty is uncertain, but a large systematic review shows no difference in complications between those who received cranioplasty before 3 months, compared to after 3 months since operation. ${ }^{56}$

\section{Limitations and Recommendations}

The thresholds from our data can guide decisionmaking in STBI patients with traumatic mass lesions. Still, while our work is prospective, it is a single centre evaluation with no control group, thus having the limitations associated with these methodological restrictions. Additionally, our relatively small sample size reduces the precisions of the estimates of our prognostic factors; thus, a larger sample size would be necessary to reduce the width of the confidence intervals and increase our certainty, allowing us to make a more accurate prediction of the impact of GCS, and midline shift changes on the outcome.

Our research shows that factors for a poor outcome such as GCS of $3-5$, midline shift of $7.5 \mathrm{~mm}$ or more, age greater than 50 years and a volume of mass lesions greater than $40 \mathrm{ml}$ can be factors that should be considered before planning a DC in patients with a large traumatic mass lesion. Crucially, family input must also be considered an essential factor while determining the degree of disability from which the patient will suffer.

\section{CONCLUSION}

Unilateral decompressive hemicraniectomy is an important procedure in managing severe traumatic brain injury patients with traumatic mass lesions and improves functional outcomes in select cases. A GCS $(5-8)$, midline shift of $7.5 \mathrm{~mm}$ or less, are two important variables that can stratify patients who are likely to benefit from DHC.

\section{REFERENCES}

1. Stocchetti N, Maas AIR. Traumatic Intracranial Hypertension. New Engl J Med 370. 2014;22 SRC BaiduScholar:2121-30.

2. Talsky A, Pacione LR, Shaw T, Wasserman L, Lenny AM, Verma $A$, et al. 1). Pharmacological interventions for traumatic brain injury. Journal. 53 (1 SRC - Baidu Scholar): 26-31.

3. Bhatti J, Stevens K, Mir M, Hyder AA, Razzak J. Emergency care of traumatic brain injuries in Pakistan: a multicenter study. BMC Emerg Med. 2015; 15 Suppl. 2 (Suppl. 2): S12.

4. Junaid M, Afsheen A, Tahir A, Bukhari SS, Kalsoom A. Changing spectrum of traumatic head injuries: 
Demographics and outcome analysis in a tertiary care referral centre. J Pak Med Assoc. 2016; 66 (7): 864-8.

5. Marshall LF. Head injury: recent past, present, and future. Neurosurgery, 2000; 47 (3): 546-61.

6. Prabhu AJ, Matta BF. Anaesthesia for extra-cranial surgery in patients with traumatic brain injury. Critical Care Pain. 2004; 4 (5 SRC - Baidu Scholar): 156-9.

7. Jaeger $M$, Soehle $M$, Meixensberger J. Effects of decompressive craniectomy on brain tissue oxygen in patients with intracranial hypertension. J Neurol Neurosurg Psychiatry, 2003; 74( 4): 513-5.

8. Cianchi G, Bonizzoli M, Zagli G, di Valvasone $S$, Biondi $S$, Ciapetti $M$, et al. Late decompressive craniectomy after traumatic brain injury: neurological outcome at 6 months after ICU discharge. J Trauma Manag Outcomes, 2012; 6 (1): 8.

9. Honeybul S, Ho KM, Gillett GR. Reconsidering the role of decompressive craniectomy for neurological emergencies. J Crit Care, 2017; 39: 185-9.

10. Park J-H, Park J-E, Kim S-H, Lim Y-C, You N-K, Ahn $\mathrm{Y}-\mathrm{H}$, et al. Outcomes of Ultra-Early Decompressive Craniectomy after Severe Traumatic Brain InjuryTreatment Outcomes after Severe TBI. Korean Journal of Neurotrauma, 2014; 10 (2): 112-8.

11. Rubiano AM, Villarreal W, Hakim EJ, Aristizabal J, Hakim F, Dìez JC, et al. Early decompressive craniectomy for neurotrauma: an institutional experience. Ulusal travma ve acil cerrahi dergisi = Turkish journal of trauma \& emergency surgery: TJTES. 2009; 15 (1): 28-38.

12. King JT, Jr., Carlier PM, Marion DW. Early Glasgow Outcome Scale scores predict long-term functional outcome in patients with severe traumatic brain injury. J Neurotrauma, 2005; 22 (9): 947-54.

13. Marshall L, Marshall $S$, Klauber $M$, Clark $M$, Eisenberg $\mathrm{H}$, Jane $\mathrm{J}$, et al. A new classification of head injury based on computerized tomography. Journal of Neurosurgery, 1991; 75 Supplement: S14-S20SRC - Baidu Scholar.

14. Fotakopoulos G, Tsianaka E, Vagkopoulos K, Fountas KN. According to which factors in severe traumatic brain injury craniectomy could be beneficial. Surg Neurol Int. 2016; 7: 19-.

15. Kjellberg RN, Prieto A, Jr. Bifrontal decompressive craniotomy for massive cerebral edema. J Neurosurg. 1971; 34 (4): 488-93.

16. Ong YK, Goh KY, Chan C. Bifrontal decompressive craniectomy for acute subdural empyema. Childs Nerv Syst. 2002; 18 (6-7): 340-3; Discussion 4.

17. Wani AA, Dar TI, Ramzan AU, Malik NK, Kirmani $A R$, Bhatt $A$, et al. Decompressive craniectomy in head injury. The Indian Journal of Neurotrauma, 2009; 6 (2): 103-10.

18. Ziai WC, Port JD, Cowan JA, Garonzik IM, Bhardwaj A, Rigamonti D. Decompressive craniectomy for intractable cerebral edema: experience of a single center. J Neurosurg Anesthesiol. 2003; 15 (1): 2532.

19. Arabi YM, Haddad SH. Critical care management of severe traumatic brain injury in adults.

20. Howard JL, Cipolle MD, Anderson M, Sabella V, Shollenberger $\mathrm{D}$, Li PM, et al. Outcome after decompressive craniectomy for the treatment of severe traumatic brain injury. The Journal of trauma, 2008; 65 (2): 380-5; Discussion 5.

21. Hosseinali K, Amin N, Fariborz G, Arash K, A. Outcome Determinants of Decompressive Craniectomy in Patients with Traumatic Brain Injury; Center Experience from Southern Iran. Bulletin of Emergency and Trauma, 2017; 5 (3 SRCBaidu Scholar): 190-6.

22. Grille $\mathrm{P}$, Tommasino N. Decompressive craniectomy in severe traumatic brain injury: prognostic factors and complications. Rev Bras Ter Intensiva. 2015; 27 (2): 113-8.

23. Gouello G, Hamel O, Asehnoune K, Bord E, Robert $\mathrm{R}$, Buffenoir K. Study of the long-term results of decompressive craniectomy after severe traumatic brain injury based on a series of 60 consecutive cases. Scientific World Journal, 2014; 2014: 207585.

24. Cooper DJ, Rosenfeld JV, Murray L, Arabi YM, Davies AR, D'Urso P, et al. Decompressive craniectomy in diffuse traumatic brain injury. $\mathrm{N}$ Engl J Med. 2011; 364 (16): 1493-502.

25. Laghari AA, Bari ME, Waqas M, Ahmed SI, Nathani KR, Moazzam W. Outcome of Decompressive Craniectomy in Traumatic Closed Head Injury. Asian Journal of Neurosurgery, 2018; 13 (4): 10536.

26. Choudhary N, Bhargava R. Decompressive craniectomy in diffuse traumatic brain injury: An industrial hospital study. Asian Journal of 
Neurosurgery, 2018; 13 (2): 314-8.

27. Huang $X$, Wen L. Technical considerations in decompressive craniectomy in the treatment of traumatic brain injury. International Journal of Medical Sciences, 2010; 7 (6): 385-90.

28. Hutchinson PJ, Kolias AG, Timofeev IS, Corteen EA, Czosnyka $M$, Timothy $J$, et al. Trial of Decompressive Craniectomy for Traumatic Intracranial Hypertension. The New England Journal of Medicine, 2016; 375 (12): 1119-30.

29. Sharda $P$, Haspani $S$, Idris $Z$. Factors prognosticating the outcome of decompressive craniectomy in severe traumatic brain injury: A Malaysian experience. Asian Journal of Neurosurgery, 2014; 9 (4): 203-12.

30. Shibahashi K, Sugiyama K, Okura Y, Hoda H, Hamabe Y. Multicenter Retrospective Cohort Study of "Talk and Die" After Traumatic Brain Injury. World Neurosurg. 2017; 107: 82-6.

31. Han JX, See AAQ, Gandhi M, King NKK. Models of Mortality and Morbidity in Severe Traumatic Brain Injury: An Analysis of a Singapore Neurotrauma Database. World Neurosurg. 2017; 108: 885-93.e1.

32. Quattrocchi KB, Prasad P, Willits NH, Wagner FC. Quantification of midline shift as a predictor of poor outcome following head injury. Surgical Neurology, 1991; 35 (3): 183-8.

33. Perel $P$, Roberts I, Bouamra $O$, Woodford $M$, Mooney J, Lecky $F$, et al. Intracranial bleeding in patients with traumatic brain injury: A prognostic study. Medicine and Extracranial complications of severe head injury Journal of Neurosurgery, 1992; 776 pp. 9 (1 SRC - Baidu Scholar): 901-7.

34. Balasubramanian $H$, Saravanan $S$, Niban G, Raj TG. Efficacy of Decompressive Craniectomy in Acute Subdural Hematoma in Head Injury Patients, Madurai Medical College, Madurai.

35. Yılmaz İ, Ertem DH, Kılıç M, Altaş K, Mirhasilova M, Ozdemir B, et al. Factors associated with mortality in acute subdural hematoma: Is decompressive craniectomy effective? Ulus Travma Acil Cerrahi Derg. 2019; 25 (2): 147-53.

36. Mori K, Nakao Y, Yamamoto T, Maeda M. Early external decompressive craniectomy with duroplasty improves functional recovery in patients with massive hemispheric embolic infarction: timing and indication of decompressive surgery for malignant cerebral infarction. Surg
Neurol. 2004; 62 (5): 420-9; Discussion 9-30.

37. Polin RS, Shaffrey ME, Bogaev CA, Tisdale N, Germanson T, Bocchicchio B, et al. Decompressive bifrontal craniectomy in the treatment of severe refractory posttraumatic cerebral edema. Neurosurgery, 1997; 41 (1): 84-92; Discussion - 4.

38. Eghwrudjakpor PO, Allison AB. Decompressive craniectomy following brain injury: factors important to patient outcome. Libyan J Med. 2010; 5: 10.4176/091104.

39. Van Veen $E$, Aerdts $S$, van den Brink W. Decompressive (hemi) craniectomy for refractory intracranial hypertension after traumatic brain injury. Critical Care, 2006; 10 (1): 1 -.

40. Stiver SI. Complications of decompressive craniectomy for traumatic brain injury. Neurosurg Focus, 2009; 26 (6): E7.

41. Georgiadis D, Schwarz S, Aschoff A, Schwab S. Hemicraniectomy and moderate hypothermia in patients with severe ischemic stroke. Stroke, 2002; 33 (6): 1584-8.

42. Phan K, Moore JM, Griessenauer C, Dmytriw AA, Scherman DB, Sheik-Ali $S$, et al. Craniotomy Versus Decompressive Craniectomy for Acute Subdural Hematoma: Systematic Review and Meta-Analysis. World Neurosurg. 2017; 101: 677-85.e2.

43. Picetti $E$, Caspani ML, laccarino C, Pastorello G, Salsi $P$, Viaroli $E$, et al. Intracranial pressure monitoring after primary decompressive craniectomy in traumatic brain injury: a clinical study. Acta Neurochir (Wien). 2017; 159 (4): 61522.

44. Hayman EG, Kurland DB, Grunwald Z, Urday S, Sheth KN, Simard JM. Decompressive Craniectomy in Neurocritical Care. Semin Neurol. 2016; 36 (6): 508-19.

45. Grindlinger GA, Skavdahl DH, Ecker RD, Sanborn MR. Decompressive craniectomy for severe traumatic brain injury: clinical study, literature review and meta-analysis. Springerplus, 2016; 5 (1): 1605.

46. Piek J, Chesnut RM, Marshall LF, van Berkum-Clark $M$, Klauber MR, Blunt BA, et al. Extracranial complications of severe head injury. J Neurosurg. 1992; 77 (6): 901-7.

47. Jovanovic B, Milan Z, Markovic-Denic L, Djuric O, Radinovic K, Doklestic K, et al. Risk factors for ventilator-associated pneumonia in patients with 
severe traumatic brain injury in a Serbian trauma centre. International journal of infectious diseases: IJID: official publication of the International Society for Infectious Diseases, 2015; 38: 46-51.

48. Albanèse J, Leone $M$, Alliez JR, Kaya JM, Antonini $F$, Alliez $B$, et al. Decompressive craniectomy for severe traumatic brain injury: Evaluation of the effects at one year. Crit Care Med. 2003; 31 (10): 2535-8.

49. Elwatidy S. Bifrontal decompressive craniotomy for malignant brain edema. Saudi Med J. 2006; 27 (10): 1547-53.

50. Engberg $M$, Oberg $B$, Christensen KS, Pedersen $\mathrm{MB}$, Cold GE. The cerebral arterio-venous oxygen content differences (AVDO2) during halothane and neurolept anaesthesia in patients subjected to craniotomy. Acta Anaesthesiol Scand. 1989; 33 (8): 642-6.

51. Guerra WK, Gaab MR, Dietz H, Mueller JU, Piek J, Fritsch MJ. Surgical decompression for traumatic brain swelling: indications and results. Journal of Neurosurgery, 1999; 90 (2): 187-96.

52. Honeybul S. Complications of decompressive craniectomy for head injury. J Clin Neurosci. 2010; 17 (4): 430-5.

53. Waziri A, Fusco D, Mayer SA, McKhann GM, Connolly ES. Postoperative hydrocephalus in patients undergoing decompressive hemicraniectomy for ischemic or hemorrhagic stroke. Neurosurgery, 2007; 61 (3): 489-93; Discussion 93.

54. Ruf $B$, Heckmann M, Schroth I, Hügens-Penzel $M$, Reiss I, Borkhardt A, et al. Early decompressive craniectomy and duraplasty for refractory intracranial hypertension in children: results of a pilot study. Critical care (London, England), 2003; 7 (6): R133-8.

55. Cooper PR, Hagler H, Clark WK, Barnett P. Enhancement of experimental cerebral edema after decompressive craniectomy: implications for the management of severe head injuries. Neurosurgery, 1979; 4 (4): 296-300.

56. Xu $H$, Niu $C$, Fu $X$, Ding $W$, Ling $S$, Jiang $X$, et al. Early cranioplasty vs. late cranioplasty for the treatment of cranial defect: A systematic review. Clin Neurol Neurosurg. 2015; 136: 33-40.

\section{Additional Information}

Disclosures: Authors report no conflict of interest.

Ethical Review Board Approval: The study was conformed to the ethical review board requirements.

Human Subjects: Consent was obtained by all patients/participants in this study.

Conflicts of Interest:

In compliance with the ICMJE uniform disclosure form, all authors declare the following:

Financial Relationships: All authors have declared that they have no financial relationships at present or within the previous three years with any organizations that might have an interest in the submitted work.

Other Relationships: All authors have declared that there are no other relationships or activities that could appear to have influenced the submitted work. 


\section{AUTHORS CONTRIBUTIONS}

\begin{tabular}{|l|l|l|}
\hline Sr.\# & Author's Full Name & Intellectual Contribution to Paper in Terms of: \\
\hline 1. & Naseer-ud-Din Ghulam & Literature review, methodology, manuscript writing and referencing. \\
\hline 2. & Kashif Ali Sultan & Literature review and data collection. \\
\hline 3. & Mohammad Ashraf & Literature review and manuscript writing. \\
\hline 4. & Nabeel Choudhary & Data collection and analysis of results. \\
\hline 5. & Usman Ahmad Kamboh & Data collection and quality assurer \\
\hline 6. & Muhammad Asif Raza & Literature review, data collection and quality assurer. \\
\hline 7. & Nazir Ahmed & Data collection and quality assurer. \\
\hline 8. & Waqas Latif & Statistical Analysis. \\
\hline 9. & Syed Shahzad Hussain & Study design and methodology. \\
\hline 10. & Naveed Ashraf & Study design and methodology. \\
\hline
\end{tabular}

